\section{¿CÓMO, POR QUIÉN Y PARA QUÉ? INVESTIGACIÓN Y LABOR CREATIVA EN EL ESTUDIO DE DESASTRES EN PUERTO RICO}

Tania López Marrero ${ }^{1^{*}}$ y Tamara Heartsill Scalley ${ }^{2}$

\section{RESUMEN}

En el año 2017 el huracán María impactó el archipiélago de Puerto Rico como un huracán de categoría 4. A raíz de esa experiencia surge el libro Un cambio categoría 4: Memorias del huracán María, el cual incluye las narrativas personales de 15 estudiantes de pregrado de la Universidad de Puerto Rico. En este artículo documentamos el proceso de producción y diseminación del libro. Describimos cómo dicho proceso representó un mecanismo para afrontar las condiciones posteriores al desastre, además de aportar al desarrollo académico y profesional de los estudiantes. Ejemplificamos cómo el libro contribuye a las aspiraciones del manifiesto 'Poder, prestigio y valores olvidados: Un manifiesto de los estudios sobre desastres', el cual destaca, entre otras cosas, la necesitad de producción de conocimiento por parte de aquellos que sufren los impactos de los desastres de manera que se reflejen adecuadamente las realidades locales en las que se desatan los desastres y que, además, redunden en beneficio a aquellos que viven en riesgo y experimentan los mismos. En ese contexto reflexionamos y sugerimos unas áreas de énfasis para adelantar los objetivos del manifiesto, de manera específica, y del estudio de desastres y reducción de riesgo, de manera más amplia.

\section{PALABRAS CLAVES}

Desastres, Narrativa personal, Participación, Comunicación, Reflexión, Investigación de pregrado, Labor creativa, Huracán María, Puerto Rico

\section{WHAT FOR, HOW AND BY WHOM? RESEARCH AND CREATIVE ACTIVITY IN THE STUDY OF DISASTERS IN PUERTO RICO}

\section{ABSTRACT}

In 2017, Hurricane Maria impacted the archipelago of Puerto Rico as a category 4. As a result of this experience, the book 'Un cambio categoría 4: Memorias del huracán María'- which includes the personal narratives of 15 undergraduate students from the University of Puerto Rico-was produced. In this article we document the book's production and dissemination process. We describe how this process represented a mechanism for coping with post-disaster conditions, as well as contributing to the academic and professional development of students. We exemplify how the book contributes to the aspirations of 'Power, Prestige \& Forgotten Values: A Disaster Studies Manifesto', which highlights, among other things, the need for knowledge production by those who suffer the impacts of disasters in a way that adequately reflects the local realities in which disasters occur; the Manifesto also advocates that knowledge production should benefit those who live at risk and experience disasters. In this context, we reflect and suggest areas to advance the objectives of the Manifesto, specifically, and the study of disasters and risk reduction, more broadly.

\section{KEYWORDS}

Disasters, Personal narrative, Participation, Communication, Reflection, Undergraduate research, Creative activity, Hurricane María, Puerto Rico
1. Departamento de Ciencias Sociales \& Centro Interdisciplinario de Estudios del Litoral, Universidad de Puerto Rico - Recinto de Mayagüez, Mayagüez, Puerto Rico.

2. International Institute of Tropical Forestry, USDA Forest Service \& Departamento de Ciencias Ambientales, Universidad de Puerto Rico - Recinto de Río Piedras, San Juan, Puerto Rico.

*Autor de correspondencia: tania.lopezı@upr.edu

Identificador:

http://revistareder.com/ handle-o719-8477-2021-110

\section{RECIBIDO}

9 de febrero de 2021

\section{ACEPTADO}

22 de abril de 2021

\section{PUBLICADO}

1 de julio de 2021

\author{
Formato cita \\ Recomendada (APA): \\ López Marrero, T. \& \\ Heartsill Scalley, T. (2021). \\ ¿Cómo, por quién y para \\ qué? Investigación y labor \\ creativa en el estudio \\ de desastres en Puerto \\ Rico. Revista de Estudios \\ Latinoamericanos sobre \\ Reducción del Riesgo de \\ Desastres REDER, 5(2), 107- \\ 124. http://revistareder.com/ \\ handle-0719-8477-2021-110
}

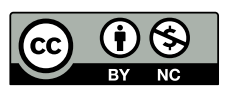

Todos los artículos publicados en REDER siguen una política de Acceso Abierto y se respaldan en una Licencia CreativeCommons Atribución-NoComercial 4.o Internacional.

Revista de Estudios Latinoamericanos sobre Reducción del Riesgo de Desastres (REDER)

Diseño: Lupe Bezzina 


\section{INTRODUCCIÓN}

Los eventos de desastres resultan en el desarrollo de proyectos e investigaciones donde, en muchos casos, la conceptualización, los enfoques y las metodologías utilizadas son establecidas por investigadores ajenos al lugar del desastre 0 , inclusive, por investigadores locales "bien establecidos" en ciertas áreas y disciplinas. En el caso de Puerto Rico, y en parte por su relación política con los Estados Unidos de Norteamérica (EE. UU.), la investigación luego de desastres por parte de investigadores radicados en EE. UU. es muy común. Esto lo hemos visto, por ejemplo, en el desarrollo de estudios ecológicos luego del paso de huracanes. En el caso de los estudios sobre huracanes y bosques en Puerto Rico (López Marrero et al., 2019), una mirada a los artículos publicados sobre este tema refleja que una gran cantidad son liderados por parte de investigadores afiliados a universidades estadounidenses. Más recientemente, tras el paso del huracán María (2017), investigadores y estudiantes de universidades de EE. UU. viajaron a Puerto Rico con el propósito de realizar investigaciones de respuesta rápida, llevar a cabo experiencias de aprendizaje-servicio y proveer ayuda humanitaria. Si bien estos esfuerzos pudieron ser bien intencionados, la experiencia posterior a María demostró varios aspectos de la ética de llevar a cabo investigación post desastres, y la relación investigación-universidad-comunidad, que hay que examinar y atender (Miller, 2018; RISE Network ${ }^{1}$ ). Estas preocupaciones, y la necesidad de producir guías ética- y culturalmente informadas para la investigación luego de desastres, también han sido resaltadas de manera más amplia (Gaillard \& Peek, 2019).

Aunque hay excepciones, las investigaciones por investigadores afiliados a instituciones externas al desastre o por aquellos bien posicionados culminan en publicaciones lideradas por dichos investigadores (Gaillard, 2018; Gaillard \& Gómez, 2015), adelantando así las agendas profesionales y académicas de esos investigadores. Tales investigaciones tampoco proveen, necesariamente, para el bienestar de aquellos que son estudiados y que experimentan los impactos de los desastres ni tienden a promover la reducción de riesgos a desastres en los lugares de estudio. Además, el alto volumen de investigadores e investigaciones en zonas de desastre para la recopilación de datos puede causar la llamada "fatiga de la investigación" en sobrevivientes de desastres (Clark, 2008). En esos casos, las personas locales y objeto de estudio se aturden y pueden mostrar apatía hacia la investigación, sobre todo cuando les es irrelevante para su bienestar o cuando se convierte en investigación redundante donde no se obtienen beneficios tangibles luego del desastre (Gaillard \& Peek, 2019). Estas situaciones pueden afectar la producción de conocimiento para la reducción de riesgo local.

Este tipo de investigación, que, a su vez, puede ser extractiva y excluyente en su afán de estudio de desastres es una de las preocupaciones expuestas en el manifiesto 'Poder, prestigio y valores olvidados: Un manifiesto de los estudios sobre desastres'2 (de aquí en adelante, el Manifiesto). Dicho manifiesto fue redactado por un grupo de académicos y activistas de estudios de riesgos y desastres que abogan por una investigación más inclusiva y de respeto hacia aquellos que viven en riesgo, que sufren los impactos de los desastres, que son estudiados y que aportan con sus conocimientos y experiencias. Hace alusión también al compromiso ético y a la necesidad de reconocer las aportaciones de personas locales en la producción de conocimiento y en el manejo de los desastres. Estas prácticas en los procesos de investigación han sido identificadas como problemáticas, de manera más amplia, en la literatura de descolonización de la investigación, el conocimiento, las metodologías y la educación superior (Shahjahan, et al., 2017; Smith, 2012; Stein \& Andreotti, 2016; Stein et al., 2020); dicha literatura también aboga por una mayor representación, inclusión y ética de investigación. En este contexto, el Manifiesto, en última instancia, hace un llamado a descolonizar los estudios de desastre.

En este artículo describimos el proceso de producción, publicación y diseminación del libro Un cambio categoría 4: Memorias del huracán María (López Marrero et al., 2018; de aquí en adelante, Un cambio categoría 4) y lo presentamos como un ejemplo que coincide con las aspiraciones del Manifiesto en cuanto al desarrollo de agendas de investigación y producción de conocimiento que reflejan las realidades locales y que redundan, a su vez, en beneficios de aquellos que viven en riesgo y experimentan los desastres. El artículo se divide en cinco secciones donde: (1) describimos la temporada ciclónica del 2017-con énfasis en los huracanes Irma y María y su paso por el archipiélago de Puerto Rico-y el libro Un cambio categoría 4, (2) describimos el proceso de documentación de las contribuciones del libro en relación al Manifiesto, (3) describimos y ejemplificamos la contribución del libro en el contexto de las aspiraciones del Manifiesto, (4)

1. https://therisenetwork.org

2. https://www.ipetitions.com/ petition/power-prestige-forgottenvalues-a-disaster 
describimos y reflexionamos en "cómo llegamos alli", en cuanto al proceso de producción y a los beneficios del libro, y (5) reflexionamos sobre el Manifiesto y proveemos algunas aportaciones al mismo y, de manera más amplia, al estudio de desastres y reducción de riegos.

\section{ACERCA DE LA TEMPORADA CICLÓNICA DEL 2017 Y DE UN CAMBIO CATEGORÍA 4: MEMORIAS DEL HURACÁN MARÍA}

En agosto del año 2017 un grupo de estudiantes universitarios de pregrado de la Universidad de Puerto Rico, recinto de Mayagüez, y la primera autora comenzaron a desarrollar un proyecto sobre desastres en Puerto Rico. El proyecto se desarrolló dentro del marco de estudio de la llamada "memoria social"-también conocida como memoria local, memoria colectiva 0 , simplemente, memoria-, concepto que hace referencia a las experiencias acumuladas, el conocimiento adquirido y las lecciones aprendidas a partir de desastres previos (Colten \& Giancarlo, 2011; Colten \& Sumpter, 2009; Wilson, 2013). El mismo se inició debido a que, en ese momento, habían transcurrido casi dos décadas del paso de un huracán intenso sobre Puerto Rico (el huracán Georges en el 1998), y se acercaba el centenario de un terremoto y tsunami ocurrido en el año 1918. En ese contexto recalcábamos que, aunque no habíamos experimentado un huracán intenso, terremoto o tsunami durante periodos prolongados, la localización geográfica de Puerto Rico y su situación geológica no nos eximía de su potencial ocurrencia.

El proyecto fue titulado Proyecto 1867: Desastres y memoria en Puerto Rico (ver Figura 1; de aquí en adelante Proyecto 1867). Se utilizó el 1867 como año de referencia ya que el mismo fue de gran impacto para los residentes de Puerto Rico; ese año la Isla fue impactada por un huracán intenso (el huracán San Narciso), una serie de terremotos y un tsunami (Fontán y Mera, 1868). El objetivo del proyecto era dar a conocer sobre los eventos ocurridos durante ese año, además de documentar eventos de desastres subsiguientes. Con ello, se pretendía fomentar el diálogo sobre el tema de desastres en la Isla y enfatizar la importancia de desarrollar planes de preparación y manejo a diferentes niveles. Otro de los propósitos del proyecto era-y continúa siendoproveer un espacio para que los estudiantes participantes lleven a cabo investigación y que se capaciten y adquirieran experiencia con diferentes métodos y técnicas de investigación. Así pues, comenzamos a ofrecer talleres (por ejemplo, de búsqueda de documentos de archivo, análisis de datos secundarios, entrevistas) y los estudiantes a poner en práctica dichas herramientas para buscar información, recopilar datos y documentar-a través de diferentes medios y para diferentes audiencias-eventos de huracanes, tormentas, inundaciones, deslizamientos de terreno, terremotos y tsunamis ocurridos en la Isla.

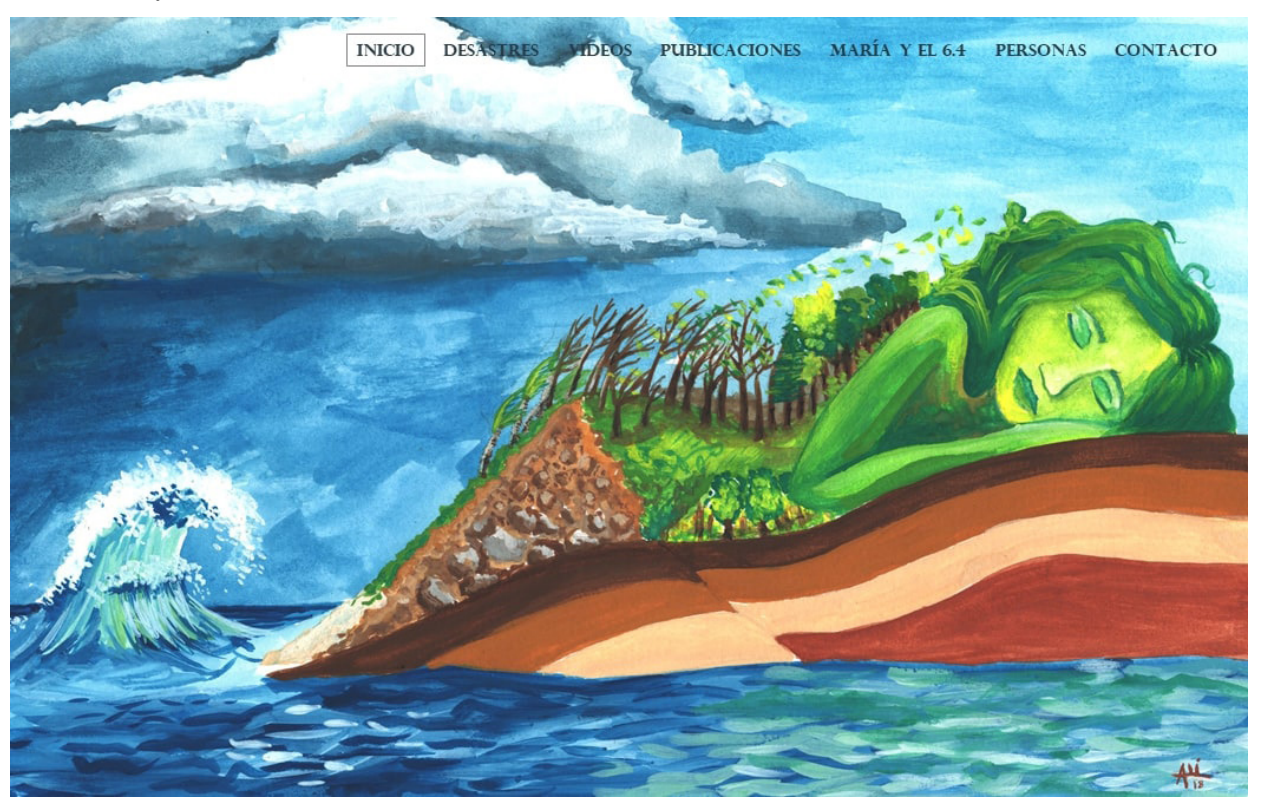

Figura 1. Página de inicio del Proyecto 1867: Desastres y memoria en Puerto Rico*

Fuente: www.proyectol867.com

* Ilustración por la estudiante investigadora Isabel A. Escalera García.

En el 2017, a poco más de un mes de haber comenzado el Proyecto 1867 y en un lapso de dos semanas, Puerto Rico fue impactado por dos huracanes intensos: Irma y María (ver Figura 2). 
El huracán Irma pasó a unos $70 \mathrm{~km}$ al noreste de Puerto Rico como un huracán de categoría 5 el 6 de septiembre y provocó daños, pérdida de bienes e interrupción de servicios básicos (agua, electricidad y comunicaciones) en muchos municipios de Puerto Rico (Cangialosi et al., 2018). Mientras, el huracán María hizo entrada por el sureste de la Isla como un huracán de categoría 4 con vientos de cerca de $250 \mathrm{~km} / \mathrm{h}$ el 20 de septiembre de 2017 . Este huracán causó una destrucción masiva en toda la Isla y exacerbó los impactos causados por el huracán Irma. Habían transcurrido cerca de 90 años en los cuales la Isla no recibía el azote de un huracán con vientos de magnitudes como los de Irma y María; el último de una magnitud cercana fue el huracán de categoría 5 , San Felipe II, en 1928 (López Marrero \& Castro Rivera, 2020). En el caso del huracán María, su trayectoria de sureste a noroeste, junto con sus intensos vientos y lluvias (Ramos-Sharrón \& Arima, 2019), resultó en el colapso de las telecomunicaciones, la falta de servicios de agua y electricidad durante meses (incluso un año en algunos lugares), el colapso de puentes y carreteras, la destrucción de viviendas, pérdidas agrícolas, inundaciones, deslizamientos de tierra, cambios en el paisaje y en la geomorfología costera, entre otros (Barreto-Orta et al., 2019; Kwasinski et al., 2019; Lugo, 2019; Pasch et al., 2019; Pérez Valentín \& Müller, 2020). Se estimó que entre 3,000 y 5,000 personas murieron por consecuencias directas e indirectas del huracán (George Washington University, 2018; Kishore et al., 2018). Los huracanes Irma y María ocurrieron en el contexto de un Puerto Rico con condiciones económicas y sociales precarias resultantes de varias décadas de recesión económica, de malas prácticas administrativas y fiduciarias, de medidas de austeridad impuestas por el gobierno de los EE. UU., y con una infraestructura (por ejemplo, vial, eléctrica y de provisión de servicios) obsoleta y débil (Benach et al., 2019; Rodríguez-Díaz, 2018). Así pues, y más allá de solamente las condiciones atmosféricas y climatológicas asociadas a los huracanes, la combinación de dichas condiciones socioeconómicas y políticas afectó la capacidad de preparación y recuperación y, en última instancia, amplificó los impactos del desastre; impactos que aún persisten mientras redactamos este artículo.

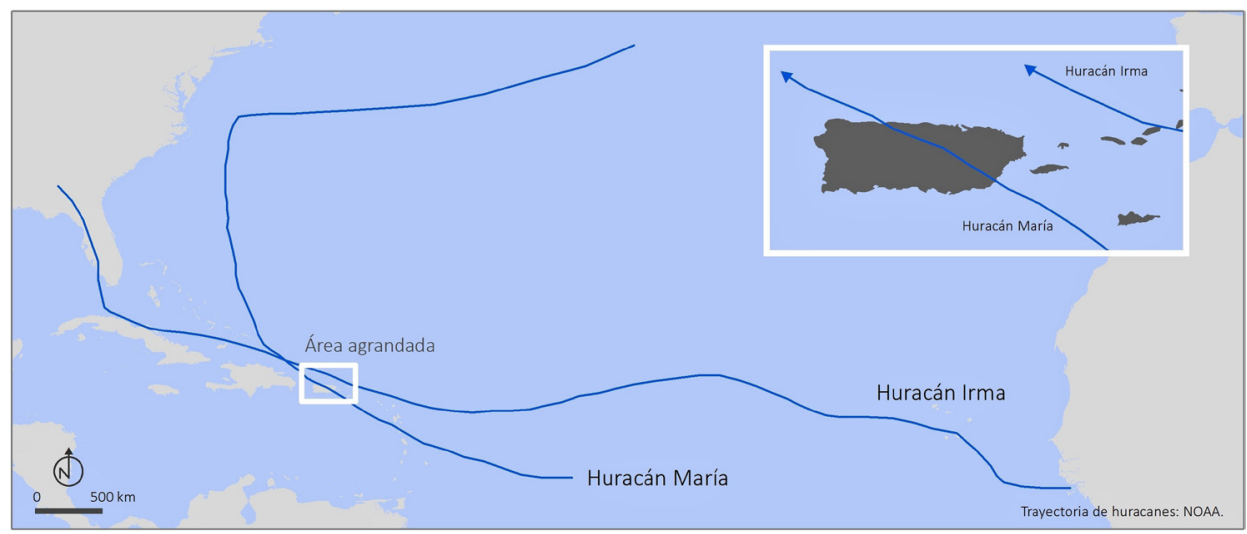

Figura 2. Trayectoria de los huracanes Irma y María en la cuenca del Atlántico y sobre- o cercano a Puerto Rico Fuente: Autoras, 2021

Al cabo de dos meses de receso académico luego del paso del huracán María, retomaron las clases en la universidad, y por ende el Proyecto 1867. Luego del inesperado evento, decidimos añadir un nuevo elemento al proyecto: que los estudiantes participantes plasmaran sus experiencias a raíz del paso del huracán y con ello contribuir a la "memoria social" del evento. Así surge el libro Un cambio categoría 4: Memorias del huracán María (ver Figura 3). El mismo proveyó un espacio para que 15 estudiantes universitarios puertorriqueños-11 mujeres y 4 hombres-que sufrieron las vicisitudes del huracán María pudieran expresar y publicar sus realidades, experiencias y puntos de vista. El proceso de producción también representó diferentes beneficios y aportó al bienestar y al desarrollo académico y profesional de los mismos. Por otra parte, su publicación en español constituye una referencia para la preparación y disminución de riesgos locales, además de constituir un recurso para los estudiosos de desastres hispanoparlantes en Latinoamérica y el Caribe, de manera específica, y de otras partes del mundo, de manera general. Además, al libro ser de libre acceso, nos aseguramos de que cualquier persona interesada en el tema pueda accederlo y utilizarlo. 


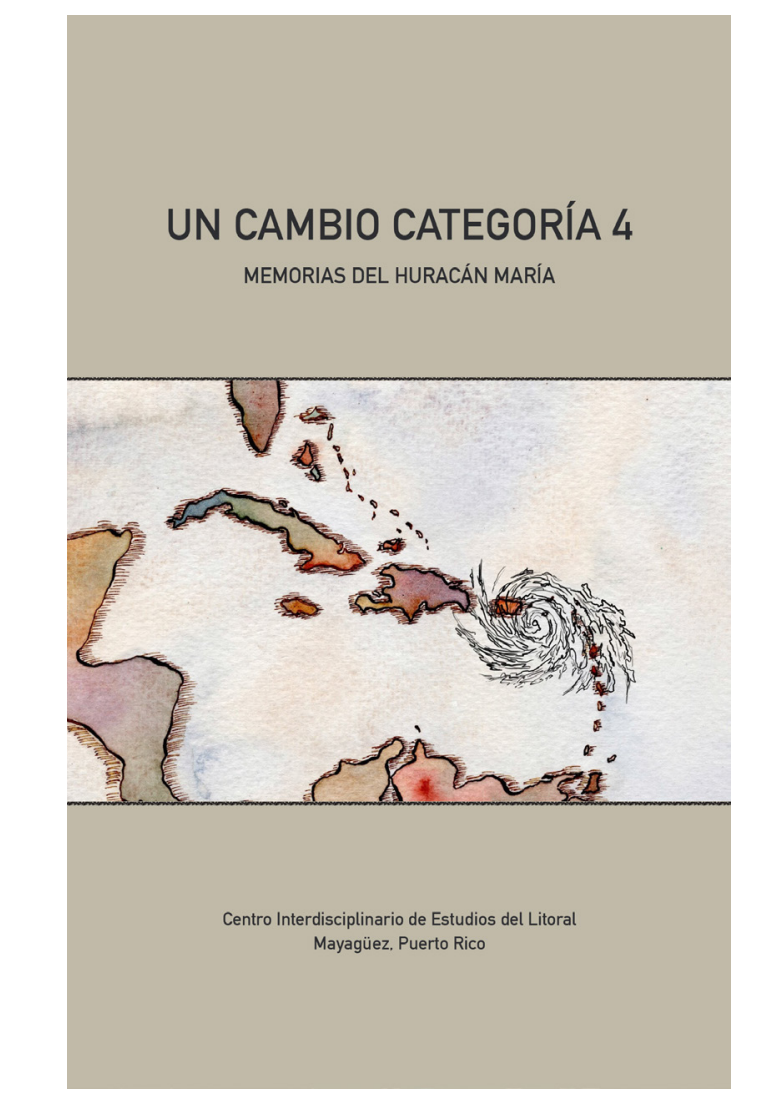

Figura 3. Portada del libro Un cambio categoría 4: Memorias del huracán María Fuente: López Marrero et al., 2018

\section{DOCUMENTANDO LAS CONTRIBUCIONES DE UN CAMBIO CATEGORÍA 4 EN RELACIÓN AL MANIFIESTO}

Para describir la relación y la aportación del libro Un cambio categoría 4 a los principios y puntos de acción del Manifiesto, nos enfocamos en tres temas: (1) el abordaje del desastre por y para las personas que los experimentan, (2) las causas fundamentales de la vulnerabilidad y los desastres según quienes experimentan los mismos, y (3) el empoderamiento y los beneficios del proceso de coproducción y publicación del estudio local de los desastres. Así, el Manifiesto constituye el marco conceptual y de referencia bajo el cual se aborda el proceso de producción del libro y su contribución al desarrollo de conocimiento y al estudio de desastres desde perspectivas locales y en beneficio de aquellos que viven y se afectan por los desastres.

Llevamos a cabo entrevistas con los estudiantes coautores del libro y utilizamos segmentos del libro para abordar los tres temas. En el caso de las entrevistas, estas se llevaron a cabo en julio de 2020, cerca de tres años del paso del huracán María y a dos años de la publicación del libro. Las preguntas de la entrevista abordaron los siguientes aspectos: (1) cómo describen la relevancia y aportación del libro, (2) qué significó para ellos redactar su narrativa personal y ser parte de la producción del libro, (3) qué destrezas desarrollaron durante el proceso de producción del libro, de manera general, y a partir de la redacción de su narrativa, de manera más específica, y (4) cómo el proceso de producción y redacción influyó en su desarrollo personal, académico o profesional. Utilizamos, e incluimos en el artículo, citas textuales tanto del libro como de las entrevistas para ejemplificar, en las palabras de los estudiantes, las áreas abordadas.

\section{UN CAMBIO CATEGORÍA 4 Y EL MANIFIESTO: POR QUIÉN Y PARA QUIÉN}

La práctica de cómo se tienden a llevar a cabo las investigaciones sobre desastres, específicamente el "por quién" y "para quién", es una de las preocupaciones expuestas en el Manifiesto (sección 1). El Manifiesto establece que las agendas de investigación, los métodos a utilizarse y la manera de diseminar los hallazgos (incluyendo quién recibe el crédito) son frecuentemente establecidas por investigadores externos al lugar donde ocurren los desastres y que están ajenos a las realidades y las circunstancias locales de aquellos que experimentan los desastres y que son objetos de 
estudio. En estudios de desastres y riesgos—sigue elaborando el Manifiesto—dicha forma de llevar a cabo investigación puede resultar en una situación donde "el riesgo cotidiano que las personas experimentan, en última instancia, se articula de manera inadecuada", además de que redunda en poco (si algún) beneficio de aquellos en riesgo y en el des-empoderamiento de las personas que son estudiados o de los investigadores locales que participan en el proceso de investigación.

Es las siguientes secciones proveemos ejemplos de cómo, a través del proceso de producción del libro Un cambio categoría 4, fomentamos la práctica de estudios de desastres llevadas a cabo por y para las personas que experimentan los desastres, basados en sus realidades y narrados por ellos: en nuestro caso los estudiantes (investigadores locales) que experimentaron el paso del huracán María. Los beneficios de la investigación donde las universidades, los estudiantes, los miembros de la comunidad y el público en general se relacionan y se nutren entre sí es cada vez más reconocida y fomentada (Trott et al., 2020).

Los desastres basados en las realidades locales y abordados por y para las personas que experimentan los mismos

Desde que comenzamos el Proyecto 1867, el proceso de investigación sobre desastres fue uno participativo, colaborativo, de constante discusión, toma de decisiones, evaluación y retroalimentación entre los investigadores: (1) qué temas y eventos incluir, (2) cómo abordarlos, (3) qué métodos utilizar, (4) cómo representar ideas y conceptos, (5) cómo diseminar los hallazgos y los resultados. Se consideró, en todo momento, los intereses y las habilidades particulares de cada estudiante, cómo ellos querían ponerlos en práctica y qué capacidades nuevas querían desarrollar. En el caso de Un cambio categoría 4, la agenda y el tema de investigación emana de las experiencias vividas por los investigadores locales, esto es, los estudiantes. Además, las narrativas están llenas de conocimiento previo al evento, el cual se ve plasmado en sus reflexiones sobre las causas y los efectos del desastre.

El proceso de redacción de las narrativas por los estudiantes, basadas en sus experiencias y circunstancias particulares, resultó en diferentes beneficios para ellos, por ejemplo, para sobrellevar el evento, para su proceso de sanación, para restablecer la normalidad (o por lo menos un poco de ella) y dar sentido al evento:

"Redactar mi experiencia significó reflexionar y darme cuenta cuán fuerte fue todo. Con todo el ajetreo luego del paso del huracán, no había tenido tiempo de 'digerir' la experiencia. Cuando me senté a escribir la narrativa, todas las emociones que había estado reprimiendo salieron a flote. Me acordé de los miedos durante el huracán, las frustraciones de las primeras semanas, la gran tristeza que sentí por mis padres y su finca, la desesperación que sintió mi hermana que vive en Estados Unidos y que estuvo varios días sin saber de nosotros. Fue terapéutico para mí sacar todas mis experiencias y emociones".

(Entrevista, estudiante universitario)

"El poder escribir mis pensamientos y experiencia significó un desahogo para mí, permitió poder liberar esa carga de mi interior y eso fue algo muy importante. Sentarme a escribir sobre mi experiencia fue un ejercicio que, si no hubiese sido por esta oportunidad, no creo que lo hubiese hecho por mi propia cuenta".

(Entrevista, estudiante universitaria)

"Para mí significa mucho poder compartir esa memoria con otros compañeros y con el lector. Fue una experiencia bien enriquecedora y liberadora. Representó sanación; poder sacar todo lo que tenía en mi mente: trauma e incertidumbre. A través de la escritura pude entender mi experiencia con más profundidad. Al escribirlo me sentí libre, como uno dice, me lo saqué del sistema".

(Entrevista, estudiante universitaria) 
También aportó al proceso de reflexión y recuperación individual, a pesar de las circunstancias luego del desastre:

"El redactar mi experiencia con el huracán María me ayudó a entender algo de los desastres: que nos podemos recuperar de ellos. Recuerdo el día después del huracán cuando no me imaginaba poder volver a vivir una vida "normal". Al momento de redactar mi experiencia no estábamos ni cerca de volver a la normalidad, pero sí habíamos progresado y nos estábamos levantando. El ejercicio de redacción me dio mucha esperanza de que podíamos volver a vivir como antes (aunque unos de una manera más rápida que otros). Los desastres ocurren y causan mucho daño y sufrimiento, pero también nos muestra cuán luchadores y resilientes podemos ser".

(Entrevista, estudiante universitario)

Por otro lado, el leer las narrativas y conocer sobre la experiencia de sus pares, ayudó a sobrellevar, de cierta manera, lo vivido:

"Leer las historias de mis compañeros me ayudó a entender que no estaba sola en este proceso y que éramos muchos en "la misma página", sin importar de qué parte de la Isla éramos. Leer el escrito de los demás nos hizo ser más empáticos, nos unió y creó conciencia entre nosotros mismos".

(Entrevista, estudiante universitaria)

"Sin duda alguna fue una de las mejores formas de plasmar un sentimiento y manejar la situación. No tan solo ayudó a sacar a flor de piel lo que sucedió aquel momento, sino poder llevar el mensaje a nuestros pares de cómo fue tu experiencia. El poder compartir algunos sentimientos nos ayudó a entender que colectivamente sufrimos, pero también nos transformamos en un mejor pueblo".

(Entrevista, estudiante universitaria)

La narración ha sido identificada como una técnica útil y apropiada para representar la diversidad de experiencias, realidades y perspectivas de aquellos que las narran o escriben; además de proveer una vía para ampliar quién habla, quién es escuchado, e incluso, quién escucha (Moezzi et al., 2017; Smith, 2012). Además, al poder compartir y comparar narrativas, se socializa lo vivido más allá de la experiencia individual y se experimenta un proceso colectivo. Por otra parte, la técnica de narrar no solamente promueve la reflexión de lo personal a lo colectivo, sino que es una manera de promover autoestima, establecer relaciones, desarrollar sentido de pertenencia, disolver jerarquías y establecer un ambiente y actitud positiva ante el aprendizaje continuo (Wylie, 2019). Un cambio categoría 4 aportó a estos procesos, resultando así en múltiples beneficios para los estudiantes y aportando al bienestar individual y colectivo.

El proceso de redacción de las narrativas también fomentó una reflexión sobre la preparación ante desastres; promoviendo así la reducción de riesgo local ante la ocurrencia de futuros eventos. Así se demostró, por ejemplo, a nivel individual y familiar:

"Redactar mi experiencia fue un proceso de constante observación sobre todo lo que acontecía a mi alrededor, una recurrente reflexión y análisis de los aspectos que mi familia y yo debemos mejorar en un próximo temporal. Dialogar con mi familia para redactar la narrativa nos permitió reflexionar sobre nuestro conocimiento sobre los desastres, pero también sobre nuestro desconocimiento, sobre todo de aquellos que no hemos experimentado aún".

(Entrevista, estudiante universitario)

Por último, el proceso de narración permitió una reflexión sobre los recursos y el acceso desigual a los mismos para la preparación y recuperación ante desastres: 
"...pude reflexionar sobre lo privilegiada que soy de haber pasado el huracán en una casa fuerte y con los recursos económicos para poder sobrellevar la crisis. Mientras que pensé muchísimo en las personas que no tuvieron las mismas facilidades que yo y que incluso lo perdieron todo".

(Entrevista, estudiante universitaria)

"El escribir sobre mi experiencia con el huracán María me ayudó también a darle un significado positivo al evento, esto, a pesar del sufrimiento y caos que generó. Permitió que valoráramos recursos como el agua y la luz, recursos que "dábamos por sentado". Por varias semanas, luego del temporal, deseábamos tener abanico para las noches, deseábamos tener agua para bañarnos a grifo y no con baldes. El huracán nos enseñó que somos, dentro de todo, afortunados y a valorar lo que tenemos y no prestábamos importancia. Nos acordó de la importancia de dar una mano al necesitado, de la ayuda mutual y del compañerismo".

(Entrevista, estudiante universitaria)

\section{Las causas fundamentales de la vulnerabilidad y el desenlace de los desastres}

Desde hace más de cuatro décadas, O’Keefe, Wesgate y Wisner (1976) hicieron hincapié en que los desastres son más una consecuencia de factores socioeconómicos que naturales. Dentro de ese contexto, el Manifiesto (sección 2) enfatiza la necesidad de que los estudios de desastres "conlleven una agenda política, que es abordar las causas fundamentales de la vulnerabilidad". A través de la redacción de las narrativas, los estudiantes pudieron reflexionar no solamente sobre su propia realidad (sección anterior), sino también sobre las diversas realidades y los factores humanos, sociales, económicos, políticos e institucionales que influyen en la vulnerabilidad de las personas (Wisner et al., 2012). Son estos factores, que en muchas ocasiones rebasan la escala geográfica y temporal de dónde ocurren los desastres, lo que en gran medida determinan el desenlace de estos.

Asociado al contexto social y humano de los desastres, una estudiante relata como:

"La experiencia de poder entrar a un hogar acompañada de los dueños, y observar cómo un lugar familiar, habitable y construido con tiempo y dedicación quedó destruido y forrado totalmente de lodo fue impactante: paredes, muebles, enseres, todo el piso y habitaciones manchadas de tierra. El relato de esa pareja, lleno de nostalgia y tristeza, conmovió a cada uno de los que estábamos allí presentes. Ciertamente, todos tenemos algo que contar sobre la experiencia ante el paso de María, pero hay quienes no quisieran tener que vivir con el recuerdo de una pérdida significativa ante tal evento. Muchos salimos de la visita a Utuado, y de aquel hogar, marcados. Nos dimos cuenta de que nuestra realidad muchas veces no se compara con la de otros. Sin duda, hay experiencias que nos hacen pensar críticamente, y más allá de lo que por lo regular en una vida cotidiana es posible".

(Un cambio categoría 4: Memorias del huracán María, 2018, p. 109)

Mientras que reflexionaron sobre cómo las condiciones socioeconómicas y de infraestructura imperantes en la Isla previo al paso del huracán agravaron el desastre; reaccionaron también a cómo el gobierno local y federal (EE. UU.) manejaron la situación después del huracán:

"El redactar sobre el desastre me ayudó a entender lo vulnerables que somos al vivir en una isla tropical a la merced de diferentes eventos naturales. También me mostró lo poco preparados que estábamos para este evento que, sin duda, fue devastador. Más allá de la preparación individual, considero que la fragilidad de la infraestructura eléctrica y la respuesta tan lenta por parte del gobierno ante la emergencia empeoró la situación".

(Entrevista, estudiante universitaria) 
"María aceleró el deslumbramiento de la crisis humanitaria que la Isla ha de manifestar por causa de la corrupción y las malas decisiones burocráticas que afectan la situación económica, ambiental y social. También se vio claramente la relación colonial y de desventaja que tenemos con Estados Unidos, al Trump venir aquí y decir que este desastre has thrown his budget out of whack".

(Un cambio categoría 4: Memorias del huracán María, 2018, p. 60)

Reaccionaron, además, al manejo del desastre a diferentes escalas, con especial atención a la respuesta "de aliento" del gobierno y resaltaron la perseverancia de las personas:

"Luego de algunos días del paso de María, la radio y el gobierno con sus famosos estribillos, comienzan a promocionar 'Puerto Rico se levanta' como la consigna de dar aliento y de superar la terrible experiencia que habíamos pasado. Cansada de un estribillo quemao' y poco cierto es porque mi escrito se titula 'Puerto Rico siempre estuvo de pie'. En medio de la tempestad, nos mantuvimos alertas, pendientes a lo que estaba ocurriendo. En medio de los vientos, los árboles se mantuvieron de pie; aun sin sus hojas frondosas dieron la batalla contra las fuertes ráfagas de vientos. Casas que, aunque sin techo, sus cimientos y paredes se mantuvieron de pie para darle la posibilidad a sus dueños de reconstruir un hogar más seguro. Estuvimos de pie en filas de varias horas para conseguir agua, gasolina, comida y hielo. Estuvimos de pie para ayudar al necesitado. La batalla la dimos y fue de pie. Puerto Rico siempre estuvo enfrentándose al huracán, que más allá de fenómeno natural es también social".

(Un cambio categoría 4: Memorias del huracán María, 2018, p. 42)

Dichas expresiones reflejan el contexto colonial, político, institucional y económico más amplio en el que se desarrollan los desastres y hacen eco a argumentos similares sobre el efecto del huracán María como el producto de desigualdades y de las causas fundamentales de la vulnerabilidad en Puerto Rico (ver, por ejemplo, Bonilla \& Lebrón, 2019; García-López, 2018; Rodríguez-Díaz, 2018).

\section{Un cambio categoría 4: Publicación, empoderamiento y beneficios}

El tema de cómo se mide el impacto, la calidad y el éxito de la investigación ha sido traído a la atención en el ámbito académico (Curry, 2018; Wouters et al., 2019), incluyendo el efecto que pueden tener en limitar la libertad académica y como supresores de la creatividad y la innovación en la investigación (Timothy, 2015). En el caso de estudios de desastres, el Manifiesto (sección 1) hace hincapié en que el impacto de la investigación se mide frecuentemente en función de las prioridades, estándares y expectativas de otros (como los organismos de donde proviene la financiación, la institución base del investigador, dónde se publican las investigaciones) en lugar de por aquellos que experimentan los desastres y son estudiados. Se tiende, además, a adelantar la agenda profesional de los investigadores externos a la cotidianidad del desastre, en lugar de los colaboradores e investigadores locales; situación que redunda, en muchos casos, en el desempoderamiento local (Gaillard \& Peek, 2019).

En el contexto de la investigación de pregrado y de la participación de estudiantes, los beneficios obtenidos son más de los esperados tradicionalmente en el ámbito académico. Por ejemplo, Seymour et al. (2004) muestra cómo estudiantes que participan en investigación obtienen múltiples beneficios, entre estos el desarrollo de destrezas de investigación, profesionales y personales, además de ayudarles a clarificar y definir sus planes futuros, ya sea en el ámbito profesional, académico o para proseguir estudios graduados. Esto, a su vez, contribuye al desarrollo de una nueva generación de investigadores y profesionales en diferentes disciplinas. En el caso del Proyecto 1867 y del desarrollo de Un cambio categoría 4, el proceso redundó en beneficios tangibles e intangibles para los estudiantes y los empoderó. Desde que iniciamos la conceptualización y el desarrollo del Proyecto 1867 y del libro, reconocimos las capacidades, habilidades e intereses de los estudiantes, las cuales pusieron en práctica. Esto aportó no solamente a ampliar habilidades y destrezas existentes, sino también a desarrollar habilidades y destrezas nuevas. Estas incluyeron, por ejemplo, destrezas de redacción, de comunicación oral, artísticas, tecnológicas, interpersonales y de trabajo en equipo: 
"Ser parte de este proyecto representó crecimiento personal, profesional y una oportunidad de trabajar y compartir con personas increíbles. Yo recibí más de lo que esperaba y llegué a tener experiencias que jamás pensé que tendría: presentaciones, publicaciones y hasta ser ilustradora de un libro y varias publicaciones. El arte es una de mis pasiones y tuve la oportunidad de desarrollarlo en el proyecto. ¡Wow! De mis mejores recuerdos de la universidad-si no el mejor". (Ver Figuras 1 y 4 ).

(Entrevista, estudiante universitaria)

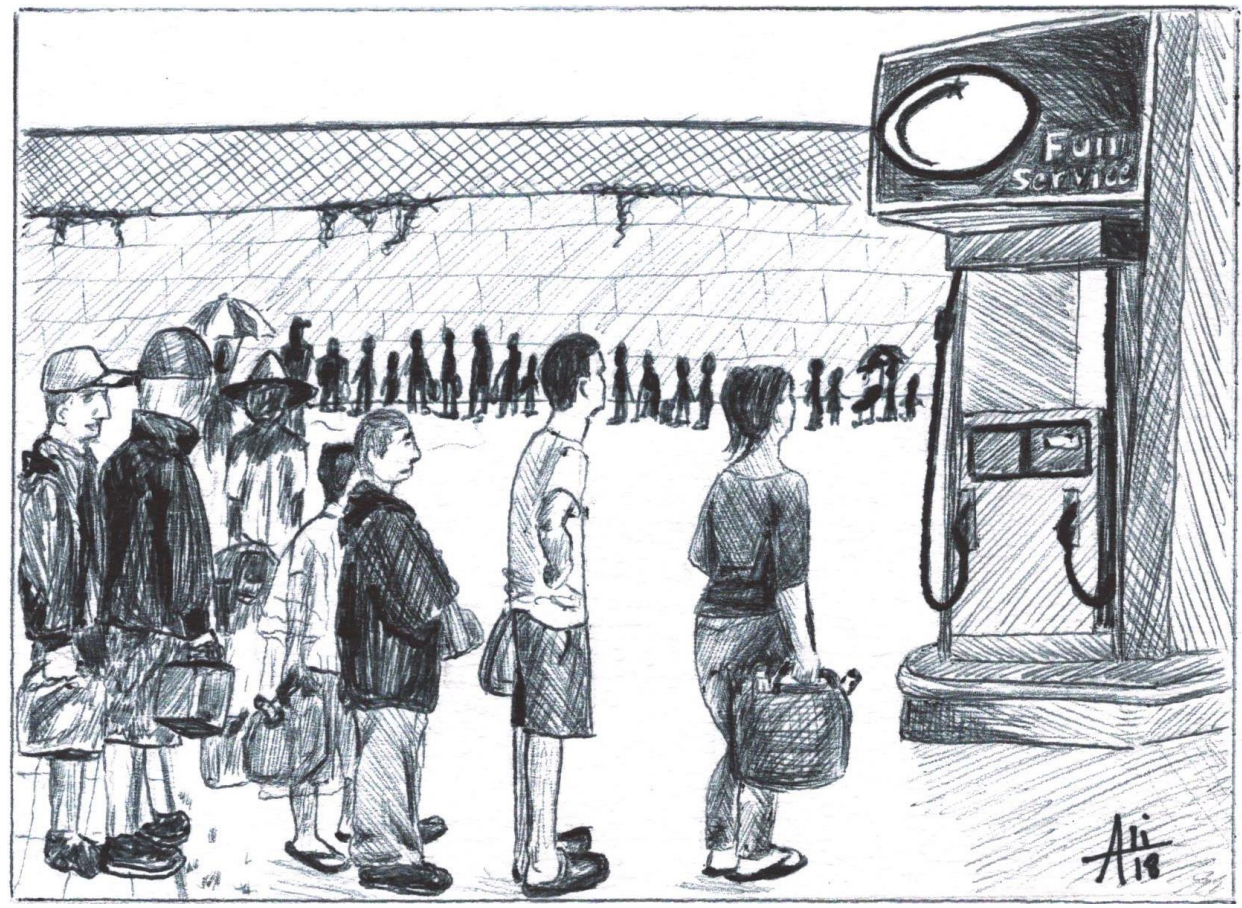

Figura 4. Ilustración 'Fría y larga espera', parte del contenido de Un cambio categoría $4^{\star}$ Fuente: López Marrero et al., 2018

* Ilustración por la estudiante investigadora Isabel A. Escalera García

"Tanto las destrezas de redacción como las destrezas interpersonales son un componente esencial en mi carrera profesional. Un cambio categoría 4 y otras publicaciones del Proyecto 1867 en las que participé son totalmente distintos a los escritos que redactaba como parte de mi bachillerato (informes técnicos y reportes de laboratorios, por ejemplo). Al ser parte de este proyecto, y al redactar mi propia narrativa, pude conocer sobre maneras alternas de comunicar una experiencia. Fue una buena integración con mi vida académica en las Ciencias Naturales. Reconocer la capacidad que tengo de poder complementar mi "mundo científico" con el social-que muchas veces los vemos tan aparte, pero que son uno-fue bien gratificante".

(Entrevista, estudiante universitario)

"El haber sido parte de este proyecto me ha ayudado profesionalmente. Luego de graduarme comencé a trabajar como maestra de Estudios Sociales. Utilizo el libro y demás productos del Proyecto 1867 para educar y concientizar a mis estudiantes sobre estas temáticas, además de utilizarlo como ejemplos de trabajo colaborativo y de investigación. Por otra parte, como maestra, tengo que llevar a cabo trabajos colaborativos y en equipo constantemente. Gracias a esta gran oportunidad, me resulta natural expresar mis ideas y escuchar atentamente a mis compañeros/as y ha facilitado el poder realizar reuniones efectivas donde logremos tomar buenas decisiones para lograr nuestros objetivos".

(Entrevista, estudiante universitaria) 
"El revisar los escritos de mis compañeros me permitió conocer los estilos de redacción y el proceso creativo de cada uno. Esto fue de beneficio para mí ya que aportó a mejorar mi propio proceso de redacción y creatividad en términos, por ejemplo, de desarrollar ideas que capten la atención de los lectores".

(Entrevista, estudiante universitario)

Tanto la participación en el Proyecto 1867 como la redacción de las narrativas aportaron, además, al desarrollo de capacidades y habilidades relacionadas a las destrezas de investigación; destrezas que han sido de utilidad tanto en su desarrollo académico como profesional, incluyendo la labor creativa:

"Gracias a este proyecto pude acercarme y hasta enamorarme del proceso de investigación, sobre todo la histórica. Amé explorar y utilizar diferentes técnicas de investigación y diseminación de resultados, amé la discusión e interacción con mis compañeros, amé el resultado final. Todo lo aprendido la aplico en mi vida personal y profesional ya que considero que este proyecto es un gran ejemplo a seguir para otros trabajos colaborativos, interdisciplinarios y educativos".

(Entrevista, estudiante universitaria)

El trabajo grupal también redundó en beneficio para los estudiantes, sobre todo el colaborar y conocer los puntos de vista y los acercamientos de estudiantes de diferentes disciplinas:

"Fue una experiencia bien enriquecedora, pues el equipo era interdisciplinario. Al trabajar con personas fuera de mi departamento entendí áreas las cuales no eran de mi especialidad. Todos nos tratamos con mucho respeto y aprendimos unos de los otros. Crecí mucho en destrezas interpersonales al trabajar con el equipo. Este trabajo en equipo también me ayudó mucho en mis destrezas de comunicación y organización".

(Entrevista, estudiante universitario)

Más allá de los beneficios y la satisfacción individual resultante de la publicación de Un cambio categoría 4, los estudiantes reconocieron la importancia de la publicación de manera más amplia para la reducción de riesgo local, el estudio de desastres en Puerto Rico y como una referencia para el estudio de desastres en general:

"Ser parte de este trabajo y haber publicado mi experiencia me llena de ilusión al saber que está disponible y puede crear un impacto positivo en nuestra sociedad".

(Entrevista, estudiante universitaria)

"...tomé aquellos recuerdos, impresiones y emociones de lo vivido a causa de María y lo plasmé de la mejor manera que pude sabiendo que alguien en algún momento lo leería. Lo que estaba compartiendo se convertiría en un pedazo de historia, algo que quedaría plasmado por generaciones. Sabía que publicar mi experiencia sería otro pequeño logro que completaría durante mi carrera universitaria en la Universidad y eso me hizo sentir muy feliz. Estas experiencias extracurriculares de alguna manera u otra te inspiran a continuar y ser mejor estudiante".

(Entrevista, estudiante universitaria)

"Es increíble saber que mi historia y la de mi familia está incorporada con otras 14, y que juntos vamos a contribuir a la educación y concienciación de lo que un fenómeno atmosférico puede hacer mental y emocionalmente a un ser humano".

(Entrevista, estudiante universitaria) 
"Estas memorias, además de ser significativas y muy personales, se convierten en cartas abiertas útiles para la reflexión individual y colectiva, análisis de investigación, entre muchas otras cosas más. También, las memorias aportan a la literatura sobre desastres en Puerto Rico tocando temas de preparación y respuesta, la eficacia de los medios de comunicación, distribución y escasez de recursos, temas de salud y bienestar, solidaridad y la construcción social de los desastres en Puerto Rico".

(Entrevista, estudiante universitaria)

"Este libro nos dio la oportunidad a nosotros, los 15 subgraduados [pregrado], de revivir lo sucedido aquel día y plasmar nuestras vivencias en papel; donde se puede conservar para siempre. Es rico en descripción, sentimiento y emoción. El mismo puede ser usado para educar a futuras generaciones de lo sucedido: alguien que jamás ha pasado por un fenómeno como un huracán, puede hojear y adentrarse a cada una de las memorias, poniéndose en los zapatos de cada uno y conociendo lo que cada uno vivió ese día".

(Entrevista, estudiante universitaria)

Durante el desarrollo de Un cambio categoría 4, los coautores dejaron de ser estudiantes para convertirse en investigadores, editores y revisores, yendo más allá y sobrepasando así su rol principal de relatores de sus experiencias con- y sobre el desastre; esto fue de gran motivación para ellos. El desarrollo y la publicación del libro empoderó a los estudiantes, los cuales vieron el resultado de su esfuerzo publicado y accesible a todo aquel interesado. Representó también una manera de reconocer y validar su trabajo, su labor creativa y el proceso de investigación. Su participación en presentaciones orales, paneles de discusión y foros abiertos sobre el Proyecto 1867 y la publicación del libro también contribuyó al proceso de empoderamiento. Por otro lado, el desarrollo de las narrativas y la publicación del libro como coautores fue un ejercicio necesario y útil para que los estudiantes_futuros investigadores y profesionales-aprendan y reflexionen profundamente sobre las prácticas responsables de autoría asociadas al proceso de publicación, donde se debe tener una participación amplia en el proceso de conceptualización, redacción y revisión, entre otras responsabilidades de autoría (Abbot et al., 2020; Weltzin et al., 2006).

\section{UN CAMBIO CATEGORÍA 4: CÓMO LLEGAMOS ALLÍ}

Las secciones 2 y 3 del Manifiesto hacen alusión al futuro que se quiere-un futuro donde las epistemologías y los relatos locales de los desastres y los riesgos puedan tener un espacio colaborativo, adecuado y justo en los estudios de desastre-y sugiere acciones para llegar, o por lo menos avanzar, hacia ese futuro deseado. En esta sección cada una de las autoras describe y reflexiona sobre "cómo llegamos alli" y el beneficio de "haber llegado alli" en el contexto de la producción de Un cambio categoría 4, de manera específica, y de los estudios de desastre en Puerto Rico de manera más general.

\section{¿Cómo llegamos allí? Notas de la primera autora}

Desde hacía mucho tiempo tenía en mente desarrollar un proyecto colaborativo de investigación y labor creativa con estudiantes sobre desastres en Puerto Rico. A mediados de agosto del 2017, y junto a un grupo de estudiantes universitarios de diferentes disciplinas, comenzamos dicho proyecto, el cual titulamos Proyecto 1867: Desastres y memoria en Puerto Rico. Jamás nos imaginamos que, a poco más de un mes de su inicio, íbamos a estar bajo los efectos del poderoso huracán María. Dicho evento nos hizo modificar algunos componentes del proyecto y decidimos, en conjunto, que los estudiantes investigadores redactaran sus propias narrativas. Redactaron sus escritos libremente, sin instrucciones predeterminadas, narrando sus experiencias a partir de sus situaciones y contextos particulares, enfatizando sus puntos de vista, temas de interés y abordajes particulares. Además, los estudiantes pusieron en práctica sus habilidades, destrezas e intereses particulares: destrezas de redacción, escritura creativa y artísticas (por ejemplo, el dibujo), entre otras. Todo esto redundó en un libro rico en descripciones y experiencias.

Como describimos en secciones anteriores, el proceso de redacción de las narrativas y la producción del libro representó sanación y resultó ser un medio donde los estudiantes expresaron sus sentimientos ante la situación. En mi caso, esto me ayudó a comprender mejor 
las diversas situaciones por la que los estudiantes habían pasado (y que aún estaban pasando) y a ser más empática. Además resultó ser un ejercicio en el cual las horas de reunión, discusión, conceptualización del libro y edición de los escritos, de una manera u otra, me ayudó a despejarme y dejar de pensar, constantemente, en el impacto del huracán, la situación del país, la situación particular de mis familiares en el centro de la isla y donde el embate del huracán fue mucho mayor, los efectos que el huracán tendría en la educación pública del país, incluyendo la Universidad (una situación ya agravada por recortes de fondos y disminución de recursos resultado de medidas de austeridad impuestas por el gobierno de EE. UU.), el efecto en los niños, las personas mayores y solas, entre otros. A la misma vez, el trabajar en este libro aseguraba que las historias de estos estudiantes, su experiencia con el huracán y sus reflexiones sobre el tema de desastres quedaran plasmadas para la posteridad.

Trabajamos el libro durante el año subsiguiente al huracán y lo publicamos y presentamos justo al año de su paso. La publicación y las presentaciones del libro resultaron ser momentos muy emotivos, tanto para mí como para los estudiantes y la audiencia; fueron muchas las felicitaciones por el logro, sobre todo hacia los estudiantes. La producción de este libro, y los trabajos de investigación y labor creativa del Proyecto 1867 en general, han sido bien gratificantes para mí. Al mismo tiempo que digo esto, también reflexiono bajo las condiciones en las que trabajamos; unas de desventaja comparados con investigadores que trabajan fuera del lugar y la cotidianidad del desastre y que hacen investigación y luego tienen la posibilidad de volver a otros espacios con todos los recursos y facilidades para la culminación del proceso de investigación y la publicación de sus resultados.

En el caso de Un cambio categoría 4, trabajamos y "llegamos alli", en muchas ocasiones sin servicio de energía eléctrica ni internet, redactando y editando "a mano", lidiando con las situaciones que vivíamos en nuestros hogares, con nuestras familias, y en el contexto del desastre de manera más amplia. En cuanto al trabajo en la universidad, producimos el libro mientras cumplíamos con nuestros compromisos docentes de enseñanza, mentoría a estudiantes, las tareas ad honorem, mientras dábamos seguimiento a otras investigaciones, entre otras responsabilidades. A pesar de esto, se publicó el libro además de ensayos fotográficos, ilustraciones, poemas y videos, entre otros, asociados a la investigación y labor creativa del tema de desastres en la Isla (ver www. proyecto1867.com). Eso nos complace y valida nuestro trabajo.

\section{Beneficios de haber llegado allí: Observaciones de la segunda autora}

Un cambio categoría 4 presenta la oportunidad de explorar una de las muchas posibles maneras de abordar un desastre, en este caso de una manera personal y colectiva mediante la narración, en primera persona, de las vivencias durante y después del huracán María. Mediante el uso de narrativas personales e ilustraciones, el libro presenta elementos que abarcan tanto una contribución académica (por la cantidad minuciosa de detalles que sirven de base para investigaciones futuras), como un producto del proceso educativo, creativo y de investigación. El libro, y el Proyecto 1867 de manera más general, provee un espacio de capacitación y validación de las experiencias de aprendizaje en métodos de investigación y de labor creativa para las próximas generaciones quienes continuarán valorando y promocionando el trabajo y la investigación de manera inclusiva y participativa.

Las investigaciones sobre desastres se benefician de perspectivas complementarias que abordan tanto lo individual como lo colectivo. Esos detalles personales y cotidianos que se afectan durante un desastre son elementos necesarios que deben incluirse en los esfuerzos de documentación de manera que aporten al análisis y desarrollo de estrategias para reducción de riesgos ante amenazas futuras. En muchas ocasiones las situaciones cotidianas y personales que surgen a raíz de un desastre pasan desapercibidas, inclusive por investigadores locales, al trabajar la investigación desde escalas más abarcadoras y con métodos más convencionales. En casos como Un cambio categoría 4, la riqueza en el contenido de las narrativas personales provee material que fortalece y amplía el marco de referencias, las fuentes y los métodos disponibles para otros investigadores y proyectos subsecuentes donde se asegura que se documente e interprete, de la manera más apropiada posible, la experiencia del desastre.

Con el ejemplo de Un cambio categoría 4 también se reafirma y materializa el compromiso de revisar y reflexionar sobre las estructuras y las prácticas de la investigación académica cuando esta, a su vez, debe responder a una realidad donde se está viviendo un desastre. Bajo estas 
condiciones, la investigación funge como herramienta para describir lo ocurrido desde el punto de vista de las personas que experimentan diferentes situaciones durante y posterior al desastre. De esta manera, se facilita un proceso terapéutico y de autovalidación para quien participa de este proceso de investigación y labor creativa.

\section{¿QUÉ NOS FALTA POR HACER? ALGUNAS REFLEXIONES Y APORTES AL MANIFIESTO}

Cuando tuvimos conocimiento de la convocatoria del número especial de REDER 'Descolonización de la ciencia de los desastres: Enfoques desde Latinoamérica y el Caribe', la cual es parte del manifiesto 'Poder, prestigio y valores olvidados: Un manifiesto de los estudios sobre desastres', vimos la relevancia de contribuir a dicho número a partir de la experiencia de producción y diseminación del libro Un cambio categoría 4 y el Proyecto 1867. En esta sección reflexionamos sobre tres puntos con el fin de aportar al Manifiesto: (1) la importancia de las narrativas personales en el estudio de desastres, (2) la necesidad de escrudiñar el asunto de lo local y lo externo y (3) las condiciones de investigación y labor creativa en situaciones desiguales y post desastres.

La narrativa, la cual se menciona someramente en el Manifiesto, es una técnica que provee múltiples beneficios tanto para quien la escribe, como para quien la lee. Para aquellos que las narran, constituye una vía para sobrellevar el desastre y comenzar a reestablecer algún grado de normalidad luego del evento (Wisner et al., 2018). El proceso de redacción de narrativas personales, y los diversos aspectos que incluyen, sirven para reflexionar sobre los factores que causan los desastres y las condiciones particulares asociadas a sus impactos. Ayuda además a entender y a dar cierto sentido al evento. Este proceso aporta, consecuentemente, a la reducción del riesgo ante futuros desastres de quien la redacta. Aporta también en la reducción de riesgo de quien la lee: el estilo de la redacción, la narración de experiencias, el sentimiento que transmiten, las referencias a lugares o eventos son elementos que pueden incitar el interés del lector en el tema en cuestión (Moezzi et al., 2017). En nuestro caso, esto se traduce a aumentar el interés en el tema de desastres y a pensar en ellos en el contexto más amplio de sus causas y manejo. Por otro lado, la función de la narrativa personal como fuente de datos y como recurso académico se ve aumentada en su alcance al estar publicada y ser, a su vez, de acceso libre. Esta accesibilidad de la información constituye una referencia para la preparación y manejo de riesgo para las personas en el lugar donde ocurre el desastre, para los estudiosos de desastres y para cualquier persona interesada en el tema. Así pues, la narrativa debe fomentarse como un método útil y apropiado para representar adecuadamente las experiencias y realidades de aquellos que viven en riesgo y son afectados por desastres; lo cual es uno de los principios promulgados en el Manifiesto.

El asunto de lo local y lo externo están expresados en múltiples secciones del Manifiesto, sobre todo en relación a los investigadores "externos" al desastre y los investigadores "locales" al desastre. Se aborda, por ejemplo, en contextos de relaciones de poder, condiciones de infraestructura y recursos para llevar a cabo investigación y en cuanto a temas de ética en la investigación. Primero, consideramos que los conceptos de "local" y "externo" se deben examinar con más detalles ya que estos pueden variar entre personas, disciplinas y según el contexto. Por ejemplo, y más allá de investigadores externos versus locales, la conversación podría girar en cuanto a la investigación y producción de conocimiento desde la cotidianidad de los lugares y los contextos asociados al desastre, además de por aquellos que han tenido sus vidas interrumpidas por un desastre. Los impactos sufridos, y la interrupción de la cotidianidad, van a variar entre las personas, aun entre aquellas que están en el mismo espacio geográfico donde ocurre el desastre. A partir de una mirada más profunda a los conceptos, se puede entender mejor para qué y por quién se investiga.

Segundo, y en cuanto al tema de relaciones de poder, si bien reconocemos estas dinámicas entre investigadores locales y externos-como se ha reconocido en los estudios de desastre (Gaillard, 2015; Gaillard \& Peek, 2019)—, se tiene que reconocer que las relaciones de poder, el potencial de explotación y la falta de reconocimiento y crédito también ocurre entre los mismos investigadores locales. Esto se puede dar sobre todo entre los investigadores locales y bien posicionados en los campos de estudio y otras personas involucradas (ya sean estudiantes, asistentes de investigación, técnicos de campo, entre otros). Así pues, tenemos que reconocer, señalar y erradicar esas dinámicas y jerarquías locales (además de las que se dan entre los locales y los externos) y desarrollar una ética de justicia e inclusión promoviendo espacios equitativos y de respeto entre los involucrados, que incluya género, edad, diversidad de conocimientos, culturas, 
acercamientos, entre otros aspectos. En el caso de Puerto Rico, y luego del huracán María, ha habido progreso en los estudios de desastre en este contexto. A partir del huracán se han generado diferentes iniciativas y publicaciones donde se han facilitado espacios para dar voz a personas locales a partir de diferentes acercamientos (por ejemplo, en el ámbito académico y en las artes). Dichos espacios han permitido la expresión del desastre, no tan solo a partir de la experiencia personal, sino también abordando las condiciones históricas, políticas y socioeconómicas más amplias asociadas a los efectos del desastre (ver, por ejemplo, Bonilla \& Lebrón, 2019; Colón \& Rodríguez, 2018; Colón et al., 2018; Orsanic \& Fusaro Martínez, 2018; Sou \& Cei, 2019). Sin embargo, aún falta mucho por hacer para una mayor inserción de todos los involucrados en las diferentes fases de la investigación, labor creatica y en la producción de conocimiento.

Otro aspecto relacionado a las dinámicas de investigación y producción de conocimiento se asocia a las condiciones desiguales de infraestructura de apoyo y recursos disponibles para la investigación. Dichas condiciones desiguales afectan la investigación y productividad en "condiciones normales" y se agravan luego de eventos extremos como cuando ocurre un desastre. Las reglas de juego académicas y de investigación para los investigadores afiliados a instituciones externas al lugar del desastre pueden ser muy distintas a la de los investigadores que viven de manera cotidiana la situación de desastre. Estas diferencias pueden incluir, por ejemplo, las cargas académicas (número de cursos que se ofrecen por semestre y número de estudiantes a atender por curso), las diferencias en apoyo académico con (o sin) asistentes de cátedra a nivel de pregrado, los comités de servicio administrativo, entre otros. Esto contrae el tiempo para completar las actividades del ciclo de la investigación (redactar propuestas, recolectar datos, escribir, publicar resultados) en situaciones post desastre. Luego de un desastre, el investigador local vive y trabaja en el "lugar de los hechos", mientras que los investigadores externos al desastre se desplazan al lugar del evento temporeramente para llevar a cabo investigación y recolección de datos, y, luego vuelven a su institución a analizar datos, redactar artículos y finalmente publicar y diseminar sus resultados. Para el investigador externo al desastre estas fases de la investigación (análisis, redacción y publicación de los resultados) ocurren, por lo general, bajo condiciones funcionales: cuando el investigador sigue teniendo acceso a servicios básicos como energía eléctrica, agua, comunicaciones, redes de apoyo, entre otros. Mientras, la investigación por investigadores locales ocurre a pesar de las faltas de servicios básicos los cuales están comprometidas en condiciones de desastre. Con esto no queremos insinuar la exclusión de- o desincentivación hacia- la investigación por parte de investigadores externos al lugar del desastre; toda producción de conocimiento es importante, complementaria y bienvenida. Lo que no debemos dejar pasar por desapercibido son las condiciones desiguales, las cuales deben ser reconocidas explícitamente para así entender y establecer la "productividad" y el "éxito" de las carreras académicas e investigativas de las personas (Curry, 2018; Timothy, 2015; Wouters et al., 2019). En cuanto a la publicación y los recursos disponibles (sobre todo recursos económicos), una manera de fomentar oportunidades accesibles es desarrollar más revistas como esta (REDER); unas que ofrecen el espacio y modalidad de libre acceso sin costo para las contribuciones de coautores. De esta manera, se promueven espacios adecuados y justos para la publicación y para aportar al estudio de desastres y disminución de riesgos.

Por último, las dinámicas de investigación entre las diferentes partes (los investigadores externos, locales y las personas estudiadas) se tienen que reconocer para el desarrollo adecuado de colaboraciones éticas y productivas, sobre todo en situaciones de post desastre. Para llevar a cabo investigaciones colaborativas dentro de una relación ética y productiva, las expectativas de participación, el diseño de investigación y la contribución en autorías deben ser explícitas. Gaillard y Peek (2019) resaltan cómo los asistentes e investigadores locales, a pesar de contribuir sustancialmente en investigaciones con investigadores externos al lugar del desastre, son usualmente relegados a coautorías en vez de reconocerse como autores principales o coautores con igual contribución a la publicación; esto, si, de hecho, se incluyen como coautores. Así pues sugerimos que, de la misma manera que hoy en día se hacen explícitas las contribuciones de cada uno de los autores al final de los artículos y se establecen de antemano las expectativas para autoría (Weltzin et al., 2006), se deben elaborar guías para colaboraciones efectivas y justas: cómo, cuándo y bajo cuáles condiciones las colaboraciones con pares externos son bienvenidas e inclusive, en ocasiones necesarias, como por ejemplo en los casos de complementariedad de recursos humanos, recursos tecnológicos, apoyo para sufragar publicaciones, entre otros. Las guías de investigación, además de establecer las expectativas y colaboraciones entre los investigadores, 
también deben establecer claramente las motivaciones y expectativas de la investigación para con los que son investigados. En este sentido, también se debe asegurar que haya oportunidades para satisfacer las necesidades locales y la obtención de algún tipo de beneficio para las personas estudiadas (Clarke, 2008). Estas guías y prácticas de colaboración-ya sea entre investigadores 0 entre investigadores y las personas que forman parte de la investigación como "sujetos de estudio"- deben tener como meta el desarrollo de investigación bajo condiciones de inclusión, mientras a su vez ser contribuciones genuinas de calidad con el fin de ser aplicado al manejo y la disminución de riesgo.

\section{AGRADECIMIENTOS}

La preparación y revisión de este artículo se benefició del insumo y los comentarios de la Dra. Elizabeth Scalley Torres, Antonio González Toro y el Dr. Alex Sloan. Agradecemos también a los estudiantes que hicieron posible el desarrollo de Un cambio categoría 4. Las aseveraciones, argumentos y conclusiones en esta publicación son únicamente de las autoras y no representan ninguna determinación ni política de la Universidad de Puerto Rico ni del USDA Forest Service.

\section{REFERENCIAS}

Abbott, L.E., Andes, A., Pattani, A.C., \& Mabrouk, P.A. (2020). Authorship Not Taught and Not Caught in Undergraduate Research Experiences at a Research University. Science and engineering ethics, 26(5), 2555-2599. https://doi.org/10.1007/s11948-020-00220-6

Barreto-Orta, M., Méndez-Tejeda, R., Rodríguez, E., Cabrera, N., Díaz, E., \& Pérez, K. (2019). State of the beaches in Puerto Rico after Hurricane María (2017). Shore E Beach, 87(1), 16-23.

Benach, J., Rivera-Díaz, M., Muñoz, N.J., Martínez-Herrero, F., \& Pericas, J.M. (2019). What the Puerto Rican hurricanes make visible: Chronicle of a public health disaster. Social Science $\mathcal{E}$ Medicine, 238, 112367.

Bonilla, Y. \& Lebrón, M. (Eds.). (2019). Aftershocks of Disaster: Puerto Rico Before and After the Storm. Haymarket Books.

Cangialosi, J.P., Latto, A. S., \& Berg, R. (2018, Junio 30). Hurricane Irma (AL112017). https://www.nhc. noaa.gov/data/tcr/AL112017_Irma.pdf

Clark, T. (2008). 'We're Over-Researched Here!': Exploring Accounts of Research Fatigue within Qualitative Research Engagements. Sociology 42(5), 953-970. https://doi. org/10.1177/0038038508094573

Colón, R., \& Rodríguez, C. (2018). María. Soda Pop Comics.

Colón, R., Silva, S., Ramán, C. J., Rodríguez, R., González, W., Santiago, Y., Sáez, D., Cruz, M., Castor, Vélez, M., Robbins, J., \& Richner, A. (2018). Nublado: Escombros de María. Soda Pop Comics.

Colten, C. E., \& Sumpter, A. R. (2009). Social memory and resilience in New Orleans. Natural Hazards 48, 355-364. https://doi.org/10.1007/s11069-0o8-9267-x

Colten, C., \& Giancarlo, A. (2011). Losing resilience on the Gulf: hurricanes and social memory. Environment, 53(4), 7-18. https://doi.org/10.1080/00139157.2011.588548

Curry, S. (2018). Words were a good start-now it is time for action. Nature, 554, 147.

Fontán \& Mera, V. (1878). La memorable noche de San Narciso y los temblores de tierra. Imprenta Comercio.

García-López, G.A. (2018). The Multiple Layers of Environmental Injustice in Contexts of (Un)natural Disasters: The Case of Puerto Rico Post-Hurricane Maria. Environmental Justice, 11(3), 101-108. https://doi.org/10.1089/env.2017.0045

Gaillard, J.C. (2018). Disaster studies inside out. Disasters, 43(1). https://doi.org/10.1111/disa.12323

Gaillard, J.C., \& Gomez, C. (2015). Post-disaster research: Is there gold worth the rush? Jàmbá: Journal of Disaster Risk Studies, 7(1), a12o. https://doi.org/10.4102/jamba.v711.120

Gaillard, J.C., \& Peek, L. (2019). Disaster-zone research needs a code of conduct. Nature, 575, 440-442.

George Washington University. (2018). Ascertainment of the Estimated Excess Mortality from Hurricane María in Puerto Rico. https://publichealth.gwu.edu/sites/default/files/downloads/ projects/PRstudy/Acertainment\%2oof\%2othe\%2oEstimated\%2oExcess $\% 20$ Mortality $\% 20$ from $\% 20$ Hurricane\%2oMaria\%2oin\%2oPuerto\%2oRico.pdf 
Kishore, N., Márques, D., Mahmud, A., Kiang, M. V., Rodríguez, I., Fuller, A., et al. (2018). Mortality in Puerto Rico after Hurricane Maria. The New England Journal of Medicine, 379(2), 162-170. https://doi. org/10.1056/NEJMsa1803972

Kwasinski, A., Andrade, F., Castro-Sitiriche, M. J., \& O’Neill-Carrillo, E. (2019). Hurricane Maria Effects on Puerto Rico Electric Power Infrastructure. IEEE Power and Energy Technology Systems Journal, 6(1), 85-94.

López Marrero, T., \& Castro Rivera, A. (2020). Actividad ciclónica en Puerto Rico y sus alrededores: 1867 al 2020. Centro Interdisciplinario de Estudios del Litoral.

López-Marrero, T., Heartsill-Scalley, T., Rivera-López, C. F., Escalera-García, I. A., \& Echevarría-Ramos, M. (2019). Broadening Our Understanding of Hurricanes and Forests on the Caribbean Island of Puerto Rico: Where and What Should We Study Now? Forests, 10, 710. https://doi.org/10.3390/ fioogo710

López-Marrero, T., Arocho-Barreto, A. Cámara-Torres, I., Castillo-Rivera, N., Castro-Rivera, A., ColónRodríguez, H. B., Escalera-García, I. A., Echevarría-Ramos, M., Franqui-Lugo, G., García-Santiago, J. D., Graniela-Marty, N., Lorenzo-Pérez, M. A., Martínez-Guzmán, L., Rivera-López, C. F., RíosSantiago, E. A., \& Sellas-Ramírez, G. E. (2018). Un cambio categoría 4: Memorias del huracán María. Centro Interdisciplinario de Estudios del Litoral.

Lugo. A. E. (2019). Social-Ecological-Technological effects of Hurricane María on Puerto Rico: Planning for Resilience Under Extreme Events. Springer.

Orsanic, L., \& Fusaro Martínez, J. (Eds.). (2018). Pa la posteridad: Antologías sobre el paso del huracán María por Puerto Rico. Ediciones del Flamboyán.

Miller, S. (2018). Creating opportunities to collaborate amidst disaster: new opportunities for academia. Cities E Health, 2(2), 130-133. https://doi.org/10.1080/23748834.2018.1522994

Moezzi, M., Janda, K. B., \& Rotmann, S. (2017). Using stories, narratives, and storytelling in energy and climate change research. Energy Research $\mathcal{E}$ Social Science, 31, 1-10. https://doi.org/10.1016/j. erss.2017.06.034

O'Keefe, P., Wesgate, K., \& Wisner, B. (1976). Taking the naturalness out of natural disasters. Nature, 260, 566-567.

Pasch R. J., Penny A. B., \& Berg, R. (2019, February 14). Tropical Cyclone Report: Hurricane Maria (AL152017). https://www.nhc.noaa.gov/data/tcr/AL152017_Maria.pdf

Pérez Valentín, J.M., \& Müller, M. F. (2020). Impact of Hurricane Maria on Beach Erosion in Puerto Rico: Remote Sensing and Causal Inference. Geographical Research Letters, e2020GLo87306. https:// doi.org/10.1029/2020GLo87306

Ramos-Sharrón, C.E., \& Arima, E. (2019). Hurricane María's Precipitation Signature in Puerto Rico: A Conceivable Presage of Rains to Come. Scientific Reports, 9, 15612. https://doi.org/10.1038/ S41598-019-52198-2

Rodríguez-Díaz, C.E. (2018). Maria in Puerto Rico: Natural Disaster in a Colonial Archipelago. American Journal of Public Health, 108(1), 30-32. https://doi.org/10.2105/AJPH.2017.304198

Seymour, E., Hunter, A. B., Laursen, S. L., \& DeAntoni, T. (2004). Establishing the benefits of research experiences for undergraduates in the sciences: First findings from a three-year study. Science education, 88(4), 493-534. https://doi.org/10.1002/sce.10131

Shahjahan, R.A., Blanco Ramírez, G., \& Andreotti, V.D.O. (2017). Attempting to Imagine the Unimaginable: A Decolonial Reading of Global University Rankings. Comparative Educational Review, 61, 51-73.

Smith, L. T. (2012). Decolonizing Methodologies: Research and Indigenous Peoples. (2da ed.). Zed Books.

Sou, G., \& Cei D. J. (2019). Después de Maria: Recuperación dia a día de desastre. University of Manchester, U.K.

Stein, S., \& Andreotti, V.D.O. (2016). Decolonization and higher education. In M. Peters (Ed.), Encyclopedia of educational philosophy and theory. Springer https://doi. org/10.1007/978-981-287-532-7_479-1

Stein, S., Andreotti, V., de Souza, L.M., Ahenakew, C., \& Suša, R. (2020). Who decides? In whose name? For whose benefit? Decoloniality and its discontents. On Education. Journal for Research and Debate, 3(7). https://doi.org/10.17899/on_ed.2020.7.1 
Timothy, D.J. (2015). Impact factors: Influencing careers, creativity and academic freedom. Tourism Management, 51, 313-315. https://doi.org/10.1016/j.tourman.2015.05.009

Trott, C.D., Sample McMeeking, L.B., \& Weinberg, A.E. (2020). Participatory action research experiences for undergraduates: forging critical connections through community engagement. Studies in Higher Education, 45(11), 2260-2273. https://doi.org/10.1080/03075079.2019.1602759

Weltzin, J.F., Belote, R.T., Williams, L.T., Keller, J.K., \& Engel, W.C. (2006). Authorship in ecology: attribution, accountability, and responsibility. Frontiers in Ecology and the Environment, 4(8), 435441. https://doi.org/10.1890/1540-9295(2006)4[435:AIEAAA]2.0.CO;2

Wilson, G. (2013). Community resilience, social memory and the post-2010 Christchurch (New Zealand) earthquakes. Area, 45(2), 207-215.

Wisner, B., Paton, D., Alisic, E., Eastwood, O., Shreve, C., \& Fordham, M. (2018). Communication with Children and Families about Disaster: Reviewing Multi-disciplinary Literature 2015-2017. Current Psychiatry Reports, 20, 73. https://doi.org/10.1007/s11920-018-0942-7

Wisner, B., Gaillard, J.C., \& Kelman, I. (2012). Framing Disasters: Theories and Stories Seeking to Understand Hazards, Vulnerability and Risk. In B. Wisner, J. C. Gaillard, \& I. Kelman (Eds.), The Routledge Handbook of Hazards and Disaster Risk Reduction (pp. 18-33). Routledge.

Wouters, P., Sugimoto, C.R., Larivière, V., McVeigh, M.E., Pulverer, B., de Rijcke, S., \& Walman, L. (2019). Rethinking impact factors: find new ways to judge a journal. Nature, 569, 621-623.

Wylie, C.D. (2019). Socialization through stories of disaster in engineering laboratories. Social studies of science, 49(6), 817-838. https://doi.org/10.1177/0306312719880266 